\title{
Complete genome sequence of lytic bacteriophage RG-2014 that infects the multidrug resistant bacterium Delftia tsuruhatensis ARB-1
}

\author{
Ananda Shankar Bhattacharjee ${ }^{1,4}$, Amir Mohaghegh Motlagh 1,5, Eddie B. Gilcrease², Md Imdadul Islam', \\ Sherwood R. Casjens ${ }^{2,3}$ and Ramesh Goel ${ }^{1 *}$
}

\begin{abstract}
A lytic bacteriophage RG-2014 infecting a biofilm forming multidrug resistant bacterium Delftia tsuruhatensis strain ARB-1 as its host was isolated from a full-scale municipal wastewater treatment plant. Lytic phage RG-2014 was isolated for developing phage based therapeutic approaches against Delftia tsuruhatensis strain ARB-1. The strain ARB-1 belongs to the Comamonadaceae family of the Betaproteobacteria class. RG-2014 was characterized for its type, burst size, latent and eclipse time periods of $150 \pm 9$ PFU/cell, 10-min, $<5$-min, respectively. The phage was found to be a dsDNA virus belonging to the Podoviridae family. It has an isometric icosahedrally shaped capsid with a diameter of $85 \mathrm{~nm}$. The complete genome of the isolated phage was sequenced and determined to be $73.8 \mathrm{kbp}$ in length with a $\mathrm{G}+\mathrm{C}$ content of $59.9 \%$. Significant similarities in gene homology and order were observed between Delftia phage RG-2014 and the E. coli phage N4 indicating that it is a member of the N4-like phage group.
\end{abstract}

Keywords: Bacteriophage, Delftia tsuruhatensis, Multidrug resistant, Biofouling, Biofilm, Genome, Podoviridae

\section{Introduction}

The occurrence and spread of antibiotic resistant bacteria in the environment are regarded as environmental challenges of highest concern in the twenty-first century. ARB bacteria are becoming common, and the Centers for Disease Control and Prevention in the United States estimates more than 23,000 patients die annually due to ARB infections in the US alone [1]. With diminishing opportunities to discover new drugs to combat ARB infections, there is an urgent need to develop alternative therapeutic methods. Phage therapy has been regarded as an alternative to the need of synthesizing new antibiotics [2].

The Delftia genus resides in the Comamonadaceae family of the Betaproteobacteria class and is a Gram negative, short rod-shaped bacterium. Delftia species are widely distributed in the environment and have

\footnotetext{
* Correspondence: ram.goel@utah.edu

${ }^{1}$ Department of Civil and Environmental Engineering, University of Utah, Salt Lake City, UT, USA

Full list of author information is available at the end of the article
}

significant biodegradation capability $[3,4]$. A recently described species, closely related to Delftia acidovorans, Delftia tsuruhatensis, has been reported to cause biofouling of bioreactor membranes [5], reverse osmosis membrane filters [6] and heating systems [7]. In addition, $D$. tsuruhatensis has been reported to be the causative agent of catheter-related nosocomial human infections $[8,9]$. Previously, we isolated a multi-drug resistant $D$. tsuruhatensis strain ARB-1 from a municipal wastewater treatment plant along with the lytic bacteriophage. We demonstrated phage based therapy to combat biofouling caused by $D$. tsuruhatensis strain $A R B-1$ with the newly isolated lytic phage as the therapeutic agent [10].

Here, we report the complete genome sequence of the lytic phage specific to $D$. tsuruhatensis ARB-1 that we named RG-2014 (it does not infect Delftia Cs1-4 or Delftia acidovorans SPH-1 (our unpublished results) [10]. The RG-2014 sequence is annotated and analyzed in order to explore its potential application as an antibiofilm bio-agent. The host of RG-2014 is multi-drug 
resistant, using it as a control agent can be an especially appropriate application. The present study is not part of a larger genomic survey.

\section{Organism information}

\section{Classification and features}

The lytic bacteriophage RG-2014 belongs to the Podoviridae family in the order Caudovirales. It is a doublestranded DNA virus that forms 1-2 mm diameter clear plaques when infecting the multidrug resistant bacterium Delftia tsuruhatensis strain ARB-1.

A sample of sludge was obtained from a local wastewater treatment plant, the Central Valley Water Reclamation Facility in Salt Lake City UT, USA. A lytic phage infecting D. tsuruhatensis ARB-1 was isolated from this sample following a previously described protocol $[11,12]$. To remove bacteria and debris the sample was sequentially filtered through 0.45 and $0.2 \mu \mathrm{m}$ filter membranes [10]. The resulting phage-containing liquid was spotted (without further concentration) on an R2A agar $(0.5 \mathrm{~g} / \mathrm{L}$ protease peptone, $0.5 \mathrm{~g} / \mathrm{L}$ yeast extract, $0.3 \mathrm{~g} / \mathrm{L} \mathrm{K}_{2} \mathrm{HPO}_{4}, 0.05 \mathrm{~g} /$ $\mathrm{L} \mathrm{MgSO}_{4} \cdot 7 \mathrm{H}_{2} \mathrm{O}, \mathrm{pH}$ 7) plate containing a lawn of $D$. tsuruhatensis ARB-1 [10]. Following incubation of the plates at $37{ }^{\circ} \mathrm{C}$ overnight, a clear plaque was picked, followed by the isolation of a second well-separated single plaque on a fresh $D$. tsuruhatensis ARB-1 lawn.

As shown in Fig. 1(a) the head of phage RG-2014 virion has a diameter of $85 \mathrm{~nm}$ and displays a hexagonal outline implying that it likely possesses icosahedral

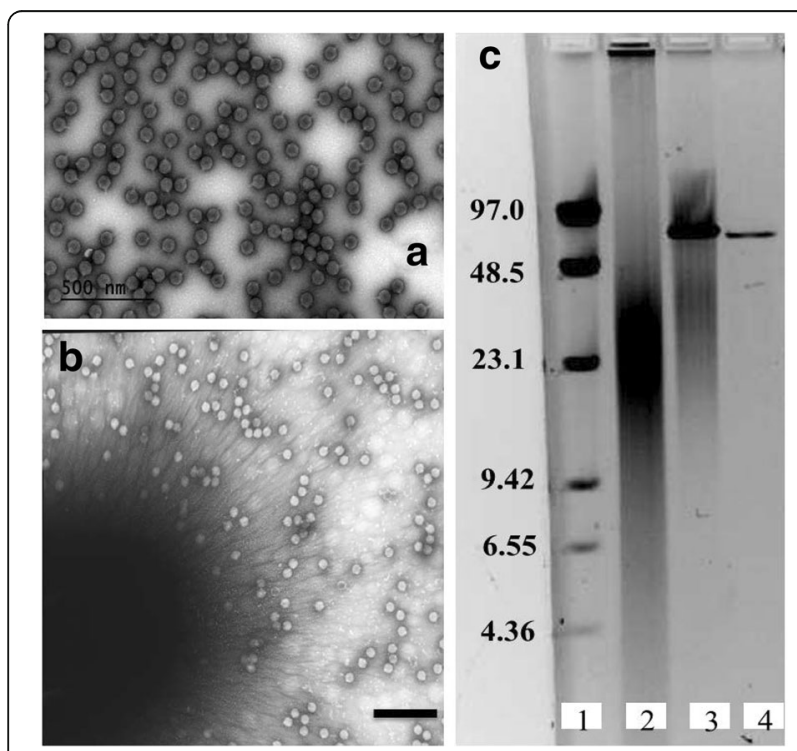

Fig. 1 Negative strain transmission electron micrographs of (a) RG-2014 virions (scale bar represents $100 \mathrm{~nm}$ ), (b) RG-2014 infecting D. tsuruhatensis ARB1 (scale bar represents 1 um) and (c) Pulsed field electrophoresis gel strained with acridine orange; Lane 1, Molecular weight marker (numbers shown are in kbp); Lane 2, 2 Mg of DNA from phage RG-2014 virions; lane 3, same as lane 2 with $0.5 \mu \mathrm{g}$ of phage DNA symmetry. It can also be seen from this transmission electron micrograph, that the virion has a very short tail, indicating that it is a member of the Podoviridae class of viruses. Figure 1(b) shows a micrograph with RG-2014 phage particles attached to a $D$. tsuruhatensis bacterial cell pili; it is not known if such pili may serve as receptor for this phage. Table 1 gives the classification and general features of RG-2014 phage. The genome of the phage is linear double-stranded DNA (dsDNA) that is about $70 \mathrm{~kb}$ in length as measured by its mobility during pulsed-field gel electrophoresis (Fig. 1(c)).

A one step growth curve was performed with the phage RG-2014 following previously described protocols [10]. The burst size, latent and eclipse period were found to be $150 \pm 9 \mathrm{PFU} /$ cell, 10 -min, and $<5$-min, respectively, at $37^{\circ} \mathrm{C}[10]$.

The complete genome sequence of the phage RG2014 was determined. The analysis of the genome clearly shows that it is a member of the N4-like phage group (see below). Grose and Casjens [11] showed that the major capsid proteins (MCPs) of virulent tailed phages parallel the evolution of the nucleotide sequence of the whole phage genome. Phylogeny of the MCPs of selected N4-like phages and other tailed phages shows that the phage RG2014's major capsid protein (identified by its similarity that of E. coli phage N4, accession no. EF056009) falls robustly within the N4-like phage group (Fig. 2).

\section{Genome sequencing information}

\section{Genome project history}

Phage RG-2014 was isolated in February of 2011, with D. tsuruhatensis strain ARB-1 as its host, The genome sequencing and analysis of phage RG-2014 was completed in December of 2016. It is the first genome sequence reported for a lytic phage infecting $D$. tsuruhatensis. The purified phage DNA was sequenced with a MiSeq Bench-top DNA sequencer (Illumina, CA) in the High-throughput Genomic Core Facility at the University of Utah. A summary of the phage RG-2014 genome sequencing information is presented below and in the Table 2.

\section{Growth conditions and genomic DNA preparation}

Phage RG-2014 virions were purified from infected $D$. tsuruhatensis ARB-1 lysates. Briefly, 0.5 L of cells were grown to $1 \times 10^{8}$ cells per $\mathrm{mL}$ in $\mathrm{R} 2 \mathrm{~A}$ medium at $37^{\circ} \mathrm{C}$ with shaking at 150 RPM [10]. The culture was then infected with five RG-2014 phages per cell, followed by incubation for $12 \mathrm{~h}$. After clear cell lysis was observed leading to a cleared culture (the cells lysed), cell debris was removed by centrifugation for $30 \mathrm{mins}$ at $5500 \times \mathrm{g}$. Phage virions were then pelleted by centrifugation overnight $(>12 \mathrm{~h})$ at $8890 \times \mathrm{g}$ at $4{ }^{\circ} \mathrm{C}$, and the pellet was re- 
Table 1 Classification and general features of Delftia tsuruhatensis ARB-1 bacteriophage RG-2014

\begin{tabular}{|c|c|c|c|}
\hline MIGS ID & Property & Term & Evidence code \\
\hline & Classification & Domain Viruses & TAS [40] \\
\hline & & Kingdom Viruses & TAS [40] \\
\hline & & Phylum: unassigned & TAS [40] \\
\hline & & Class: dsDNA viruses, no RNA phase & TAS [40] \\
\hline & & Order: Caudovirales & TAS [40] \\
\hline & & Family: Podoviridae & TAS [40] \\
\hline & & Genus: N4likevirus & TAS [40] \\
\hline & & Species: unassigned & \\
\hline & & (Type) strain: RG-2014 (KM879221.2) & \\
\hline & Gram stain & Not applicable & TAS [40] \\
\hline & Virion shape & Icosahedral & IDA \\
\hline & Motility & non-motile & IDA \\
\hline & Sporulation & Not reported & IDA \\
\hline & Temperature range & $20-38^{\circ} \mathrm{C}$ & IDA \\
\hline & Optimum Temperature & $37^{\circ} \mathrm{C}$ & IDA \\
\hline & pH range; Optimum & $6.5-7.6$ & IDA \\
\hline & Carbon Source & Host cell & IDA \\
\hline MIGS-6 & Habitat & Wastewater & IDA \\
\hline MIGS-6.3 & Salinity & Not reported & \\
\hline MIGS-22 & Oxygen & Facultative aerobic & IDA \\
\hline MIGS-15 & Biotic relationship & Obligate intracellular parasite of D. tsuruhantensis ARB-1 & IDA \\
\hline MIGS-14 & Pathogenicity & Infective phage of D. tsuruhantensis ARB-1 & IDA \\
\hline MIGS-4 & Geographic location & Central Valley Water Reclamation Facility, UT, USA & IDA \\
\hline MIGS-5 & Sample collection time & 02/01/2011, 11:00 AM & IDA \\
\hline MIGS-4.1 & Latitude & 40.7056 & IDA \\
\hline MIGS-4.2 & Longitude & 111.913953 & IDA \\
\hline MIGS-4.3 & Depth & Surface & IDA \\
\hline MIGS-4.4 & Altitude & $0 \mathrm{~m}$ & \\
\hline
\end{tabular}

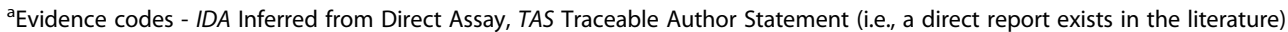

suspended in SM buffer with Gelatin $(5.8 \mathrm{~g} / \mathrm{L} \mathrm{NaCl}$, $2.0 \mathrm{~g} / \mathrm{L}, \mathrm{MgSO}_{4} .7 \mathrm{H}_{2} \mathrm{O}, 50 \mathrm{~mL} / \mathrm{L}$ of $1 \mathrm{M}$ Tris- $\mathrm{HCl} \mathrm{pH} 7.5$ and $5.0 \mathrm{~mL} / \mathrm{L}$ of a $5 \%$ solution of gelatin). Purified phage virions were obtained by $\mathrm{CsCl}$ step gradient centrifugation as described by Earnshaw et al. [12]. The purified phages were stored in SM buffer with gelatin until further use.

The purified RG-2014 virion preparation was used for phage DNA extraction according to the protocol described by Casjens and Gilcrease [13]. Briefly, $400 \mu \mathrm{L}$ of the $\mathrm{CsCl}$ purified phage particles was mixed with $75 \mu \mathrm{L}$ of lysis buffer ( $5 \mu \mathrm{L}$ of $20 \%$ SDS, $50 \mu \mathrm{L} 1 \mathrm{M}$ Tris. Cl, $20 \mu \mathrm{L}$ $0.5 \mathrm{M}$ EDTA, $\mathrm{pH}=8$ ) and incubated at $65^{\circ} \mathrm{C}$ for $15 \mathrm{~min}$. $50 \mu \mathrm{L}$ of $5 \mathrm{M}$ potassium acetate was added to the sample and incubated on ice for $1 \mathrm{~h}$. The sample was then centrifuged at $8000 \times \mathrm{g}$ for $15 \mathrm{~min}$ at $4{ }^{\circ} \mathrm{C}$, and the supernatant was carefully transferred into a new $1.5 \mathrm{~mL}$ micro-centrifuge tube. After adding $0.9 \mathrm{~mL}$ of absolute ethanol to the supernatant and inverting several times, the DNA precipitate was collected by winding it onto the tip of a sterile Pasteur pipette. The DNA precipitate was transferred into a new micro-centrifuge tube, washed with $70 \%$ ethanol by inverting a few times, and subsequently pelleted by centrifugation in a microfuge. The DNA pellet was allowed to dry at room temperature for 10-20 min and resuspended in $100 \mu \mathrm{L}$ of TE buffer (10 mM Tris-Cl pH 7.5 and 1 mM EDTA pH 8.0). About $0.1 \mu \mathrm{g}$ of the phage DNA was mixed with $5 \mu \mathrm{L}$ of loading dye and separated by $1 \%$ agarose pulsed-field gel electrophoresis (PFGE), with a 1-25-s pulse ramp, a voltage of $6.0 \mathrm{~V} / \mathrm{cm}$ with an angle of $120^{\circ}$ for $24 \mathrm{~h}$ at a constant temperature of $14{ }^{\circ} \mathrm{C}$ on a CHEF DR III system (Bio-Rad, USA). After completion of electrophoresis the gel was stained with ethidium bromide (Molecular 


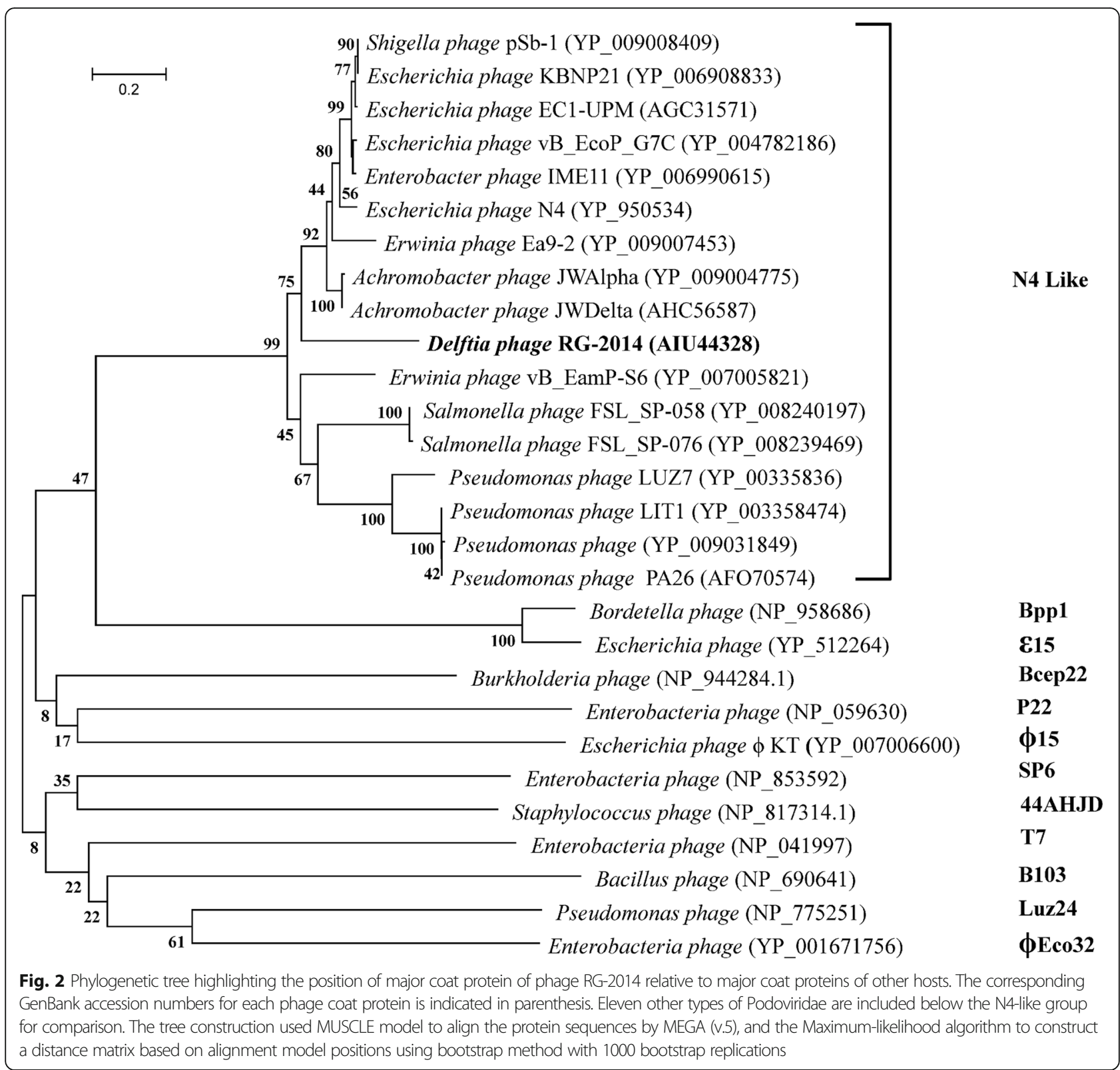

Probes, USA) and visualized under CHEM DOC gel documentation system (Bio-Rad, USA).

\section{Genome sequencing and assembly}

Approximately 8 million paired-end reads with an average length of $300 \mathrm{bp}$ were generated using a MiSeq Bench-top DNA sequencer (Illumina, CA). The reads were interleaved and trimmed based on a Phred score of 28 and a minimum post-trimming average length of 290 bp on the CLC Genomics Workbench 7.0.4 (CLC Bio, Denmark). The trimmed reads were de novo assembled on the CLC Genomics Workbench 7.0.4 with the following criteria: word size, $20 \mathrm{bp}$; automatic bubble size, 50 bp; minimum contig length, $200 \mathrm{bp}$ as described in Bhattacharjee et al. [10].

The termini of the virion chromosome were determined by dideoxynucleotide Sanger sequencing [14] using the virion DNA as a template using the following primers which direct sequencing runs off the two ends as follows; right end, $5^{\prime}$-TGCTTCATGATCTTC AGTCC-3' and left end, 5'-GAAGGCATCAGC ATGTTCAG-3'.

\section{Genome annotation}

Glimmer [15] was used to identify the open reading frames and GeneMarkS [16] for predicting genes. The predicted genes were used to search the NCBI non- 
Table 2 Project information of Delftia tsuruhatensis ARB-1 bacteriophage RG-2014

\begin{tabular}{lll}
\hline MIGS ID & Property & Term \\
\hline MIGS-31 & Finishing quality & Closed \\
MIGS-28 & Libraries used & N/A \\
MIGS-29 & Sequencing platforms & Illumina MiSeq Benchtop \\
MIGS-31.1 & Fold coverage & 20x \\
MIGS-30 & Assemblers & CLC genomics workbench \\
& & V. 7.0.3 \\
MIGS-32 & Gene calling method & GeneMarkS \\
& Locus Tag & RG2014 \\
& Genome database release & Genbank \\
& Genbank ID & KM879221.2 \\
& Genbank Date of Release & Oct, 8, 2014; Mar, 17, 2017 \\
& & (Corrected genome release date) \\
& GOLD ID & Go0332698 \\
& BIOPROJECT & PRJNA287956 \\
MIGS 13 & Source Material Identifier & Personal culture collection \\
& Project relevance & Virulence, Bacteriophage based \\
& & biocontrol \\
\hline
\end{tabular}

redundant database, the conserved domain database, the Cluster of Orthologous Groups database and the InterPro database and were annotated using Blast2GO 2.5.0 [17]. Automated annotation performed by Blast2GO 2.5.0 was manually curated by individually analyzing each predicted gene using BLAST against NCBI nr database with minimum e-value cut off of $10^{-3}$ [18]. ARAGORN [19] and tRNAScanSE [20] were used for detection of transfer RNA genes. The complete annotated genome sequence is available in Genbank under the accession number KM879221.

\section{Genome properties}

The lytic phage RG-2014's complete genome size was found to be 73,882 bps that includes 450 bp direct terminal repeats (we note that, when it has been examined, the genomes of other N4-like phages invariably have several hundred bp terminal repeats)with a $\mathrm{G}+\mathrm{C}$ content of $59.9 \%$. The annotation includes 88 putative protein coding ORFs and no tRNAs (Table 3). Predicted proteins were classified in COG functional categories $[21,22]$ using the WebMGA web server for metagenome analysis [23]. The number of predicted genes and the relative percentage of phage genes associated with the 25 general functional COG categories are described in Table 4. Twenty-eight (31.8\%) of the 88 genes in the RG-2014 phage genome were assigned a putative function based on significant sequence similarity to genes of known functionality in the NCBI database. Twenty-one (23.8\%) genes encode putative proteins that were assigned to the conserved hypothetical protein category.
Table 3 Genome statistics

\begin{tabular}{lll}
\hline Attribute & Value & \% of Total \\
\hline Genome size (bp) & 73,882 & 100.00 \\
DNA Coding (bp) & 69,793 & 93.90 \\
DNA G + C (bp) & 44,247 & 59.90 \\
DNA scaffold & 0 & 0.00 \\
Total genes & 88 & 100.00 \\
Protein-coding genes & 88 & 100.00 \\
RNA genes & 0 & 0.00 \\
Pseudo genes & 0 & 0.00 \\
Genes in internal clusters & 0 & 0.00 \\
Genes with function prediction & 21 & 23.86 \\
Genes assigned to COGs & 10 & 9.09 \\
Genes with Pfam domains & 12 & 13.64 \\
Genes with signal peptides & 2 & 2.27 \\
Genes with transmembrane helices & 13 & 14.77 \\
CRISPR repeats & 0 & 0.00 \\
\hline
\end{tabular}

${ }^{a}$ The total is based on either the size of the genome in base pairs or the total number of protein coding genes in the annotated genome

Additionally, 40 predicted genes (44.3\%) had no similarity to genes in the current database, and their products were classified as hypothetical proteins (Table 5). Annotation using the CDD on the NCBI server was also performed and is presented in Table 6 .

\section{Insights from the genome sequence}

The phylogenetic tree of MCPs in Fig. 2 indicates that phage RG-2014 is most closely related to the group of phages typified by Escherichia coli phage N4 (NC_008720) [13, 24-28]. In addition their hosts, E. coli K-12 and D. tsuruhatensis strain ARB-1 belong to the same phylum Proteobacteria. Table 1 summarizes the classification and general features of the phage RG-2014. BLAST searches using the Delftia phage RG-2014 genome as a probe was undertaken to confirm this notion. Genome comparisons with $E$. coli phage N4 (NC_008720) were performed, and significant similarities in gene homology and order were observed between phages RG-2014 and N4 (Table 5 and Fig. 3). The phage RG-2014 genome shows mosaicism that is typical of tailed phages, with (for example) some regions displaying close relatedness to phage N4 (Fig. 3). Mosaicism in bacteriophage genomes is a well-known phenomenon wherein regions of high similarity are interspersed with less related or unrelated regions. These mosaic patterns in bacteriophage genomes corroborate the theory that horizontal gene transfer plays a significant role in phage evolution [29-31].

E. coli phage N4 does not depend upon its host's RNA polymerase to transcribe its early and middle genes. But encodes its own set of two RNAPs. These are encoded 
Table 4 Number of genes associated with the 25 general COG functional categories

\begin{tabular}{|c|c|c|c|}
\hline Code & Value & $\%$ age $^{a}$ & Description \\
\hline J & 0 & 0 & Translation \\
\hline A & 0 & 0 & RNA processing and modification \\
\hline K & 2 & 2.27 & Transcription \\
\hline L & 2 & 2.27 & Replication, recombination and repair \\
\hline B & 0 & 0 & Chromatin structure and dynamics \\
\hline D & 0 & 0 & Cell cycle control, mitosis and meiosis \\
\hline Y & 0 & 0 & Nuclear structure \\
\hline V & 0 & 0 & Defense mechanisms \\
\hline $\mathrm{T}$ & 0 & 0 & Signal transduction mechanisms \\
\hline M & 1 & 1.14 & Cell wall/membrane biogenesis \\
\hline N & 1 & 1.14 & Cell motility \\
\hline Z & 0 & 0 & Cytoskeleton \\
\hline W & 0 & 0 & Extracellular structures \\
\hline U & 0 & 0 & Intracellular trafficking and secretion \\
\hline O & 0 & 0 & $\begin{array}{l}\text { Posttranslational modification, protein turnover, } \\
\text { chaperones }\end{array}$ \\
\hline C & 0 & 0 & Energy production and conversion \\
\hline G & 0 & 0 & Carbohydrate transport and metabolism \\
\hline E & 0 & 0 & Amino acid transport and metabolism \\
\hline $\mathrm{F}$ & 2 & 2.27 & Nucleotide transport and metabolism \\
\hline $\mathrm{H}$ & 0 & 0 & Coenzyme transport and metabolism \\
\hline । & 0 & 0 & Lipid transport and metabolism \\
\hline P & 0 & 0 & Inorganic ion transport and metabolism \\
\hline Q & 0 & 0 & $\begin{array}{l}\text { Secondary metabolites biosynthesis, transport } \\
\text { and catabolism }\end{array}$ \\
\hline $\mathrm{R}$ & 2 & 2.27 & General function prediction only \\
\hline$S$ & 1 & 1.14 & Function unknown \\
\hline- & 77 & 87.5 & Not in COGs \\
\hline
\end{tabular}

${ }^{a}$ The total is based on the total number of protein coding genes in the annotated genome

by three genes, one for the early RNAP and the two subunits of the middle gene transcribing RNAP [28, 32]. The host's RNAP transcribes the N4 late genes. A striking and unique feature of this type of phage is that a unique single-subunit vRNAP is carried in the virion. vRNAP is encoded by N4 gene 50 and is injected into the host cell with the DNA where it transcribes the phage's early genes. The RNAPII that transcribes the middle genes and is encoded by the two N4 genes 15 and 16. The RG-2014 genome harbors three genes that are homologues of the N4 RNAP genes, 68, 22 and 23, respectively. The closest relatives of these RG-2014 genes are present in N4-like phages Achromobacter phage øAxp-3, Erwina phage Frozen, and Erwina phage Ea9-2, respectively (Table 5).
Most of the N4 like phages have been shown to harbor between 1 and 3 genes encoding tRNA. Paepe et al. [33] and Bailey-Bechet et al. [34] suggesting, virulent phages harbor more tRNA genes than temperate phages to ensure optimal translation leading to faster replication. However, the phage RG-2014 genome lacks transfer RNA genes, suggesting that the phage is highly adapted to its host $D$. tsuruhatensis ARB-1, with regard to codon usage, allowing it to translate its genes efficiently without the need of synthesizing its own tRNAs [24]. To support our finding average codon usage bias was calculated for the phage RG-2014 and D. tsuruhatensis CM13 (NZ_CP017420), a close representative of the host $D$. tsuruhatensis ARB-1. The average codon usage bias calculation was performed using CodonO web server (http://sysbio.cvm.msstate.edu/CodonO/) [35]. D. tsuruhatensis CM13 (NZ_CP017420) and phage RG-2014 had similar average codon usage bias of 0.440141 and 0.406048 , respectively, suggested the phage was adapted to its host.

There are two known types of virion assembly gene arrangements in the N4-like phages. First, those like phage $\mathrm{N} 4$ that have a single contiguous gene cluster that encodes all of the known structural genes and lysis proteins except the head decoration protein (N4 gene 17). Second, typified by Pseudomonas phage LIT1 in which several tail genes are present inside the replication gene cluster [25, 36]. Phage RG-2014 carries a set of homologous genes, including the separate decoration protein gene (RG-2014 gene 24), that have the phage N4 type organization. By homology to those of N4 [36], RG-2014 genes $24,68,69,71-78,83$ and 85 encode virion structural proteins.

Phage RG-2014 makes clear plaques and carries no genes that encode proteins (such as integrase or protelomerase) that might suggest a temperate lifestyle. In addition, we also recently showed that the database of bacterial genome sequences has grown to a point where relatives of essentially all known temperate phages can be found as prophages present in the reported genome sequences of their hosts [37]. Thus, absence of closely related homologous genes (the MCP gene was used in that study) in closely related host genomes of the same bacterial family is strong evidence that a phage is virulent; related prophages would be found to encode such a gene if the phage in question were temperate. In fact no genes that are closely related to MCP of the phage RG-2014 are present in the current bacterial sequence database. The closest MCP gene relatives in prophages are from the distantly related bacterial genera Mesorhizobium, Pantoea and Acinetobacter whose encoded homologous proteins are only $47-56 \%$ identical to the amino acid sequence of phage RG-2014 MCP. The latter gene matches are found (when the sequence contigs are 


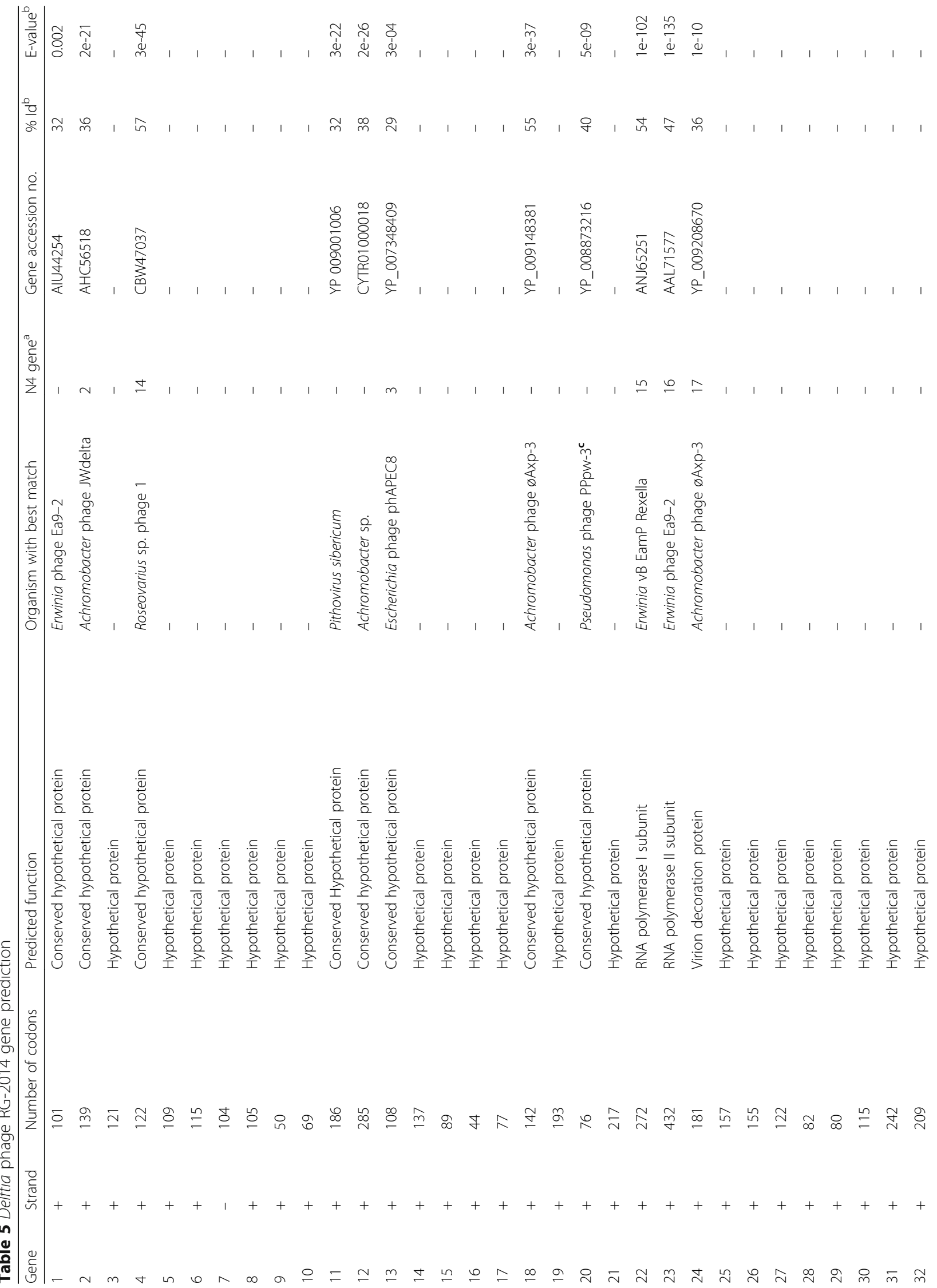




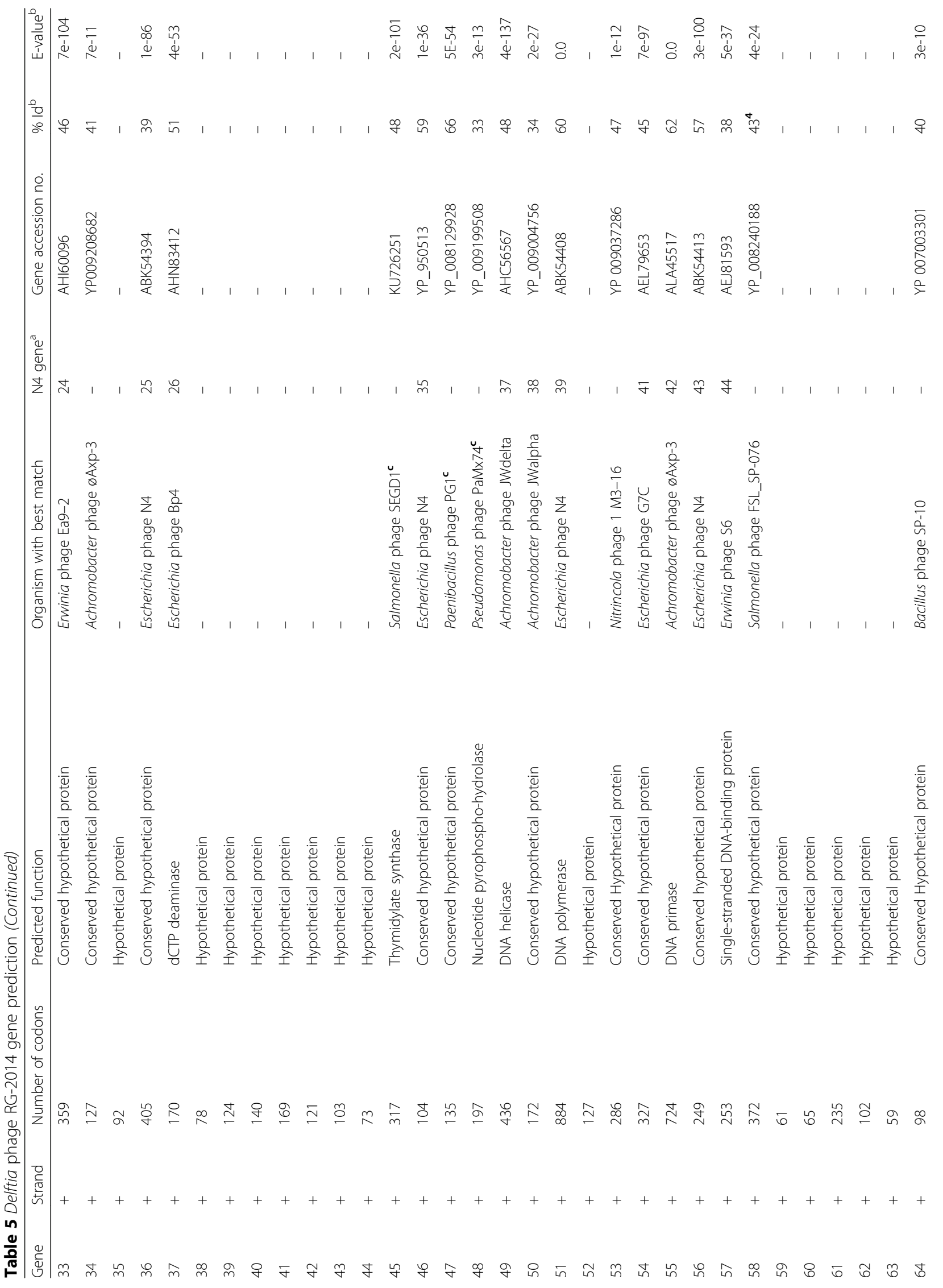




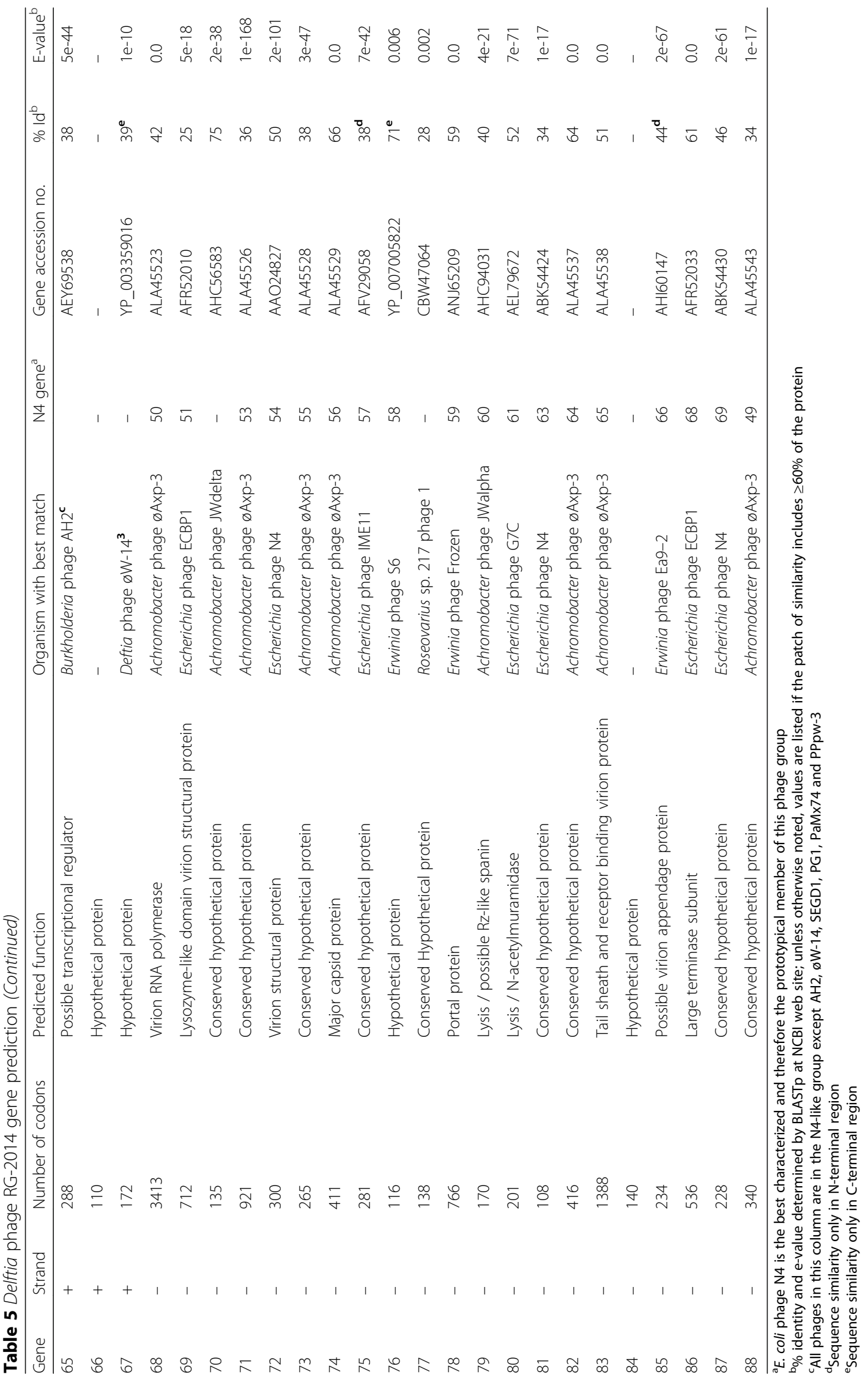


Table 6 Delftia phage RG 2014 annotation using conserved domain database*

\begin{tabular}{|c|c|c|c|c|}
\hline Gene & Evidence & E value & Bit Score & Accession \\
\hline 4 & cl10259 superfamily & $2.22 \mathrm{E}-55$ & 167.72 & Cl10259 \\
\hline 12 & MTTB superfamily & 0.004977 & 36.9774 & Cl15385 \\
\hline 15 & MDR superfamily & 0.0037317 & 33.0936 & $\mathrm{Cl} 16912$ \\
\hline 22 & Pha00452 & $1.96 \mathrm{E}-05$ & 44.2438 & Pha00452 \\
\hline 23 & RNA_pol superfamily & 4.77E-09 & 56.9554 & $\mathrm{Cl} 20211$ \\
\hline 24 & Big_2 & 0.00242 & 34.2896 & Pfam02368 \\
\hline 24 & Big_2 superfamily & 3.49E-07 & 39.6898 & $\mathrm{Cl} 02708$ \\
\hline 24 & $\operatorname{Cog} 5492$ & $3.72 \mathrm{E}-09$ & 53.2664 & $\operatorname{Cog} 5492$ \\
\hline 33 & Aaa & $6.72 \mathrm{E}-05$ & 41.3627 & Cd00009 \\
\hline 33 & ABC_atpase superfamily & $6.72 \mathrm{E}-05$ & 41.3627 & $\mathrm{Cl} 21455$ \\
\hline 36 & Vwfa & 0.0009673 & 38.3158 & Cd00198 \\
\hline 36 & Vwfa superfamily & $1.20 \mathrm{E}-20$ & 85.5169 & Cl00057 \\
\hline 36 & DUF2201_N superfamily & $9.26 \mathrm{E}-31$ & 117.611 & Cl16157 \\
\hline 37 & Trimeric_dutpase & $3.53 \mathrm{E}-13$ & 60.5857 & Cd07557 \\
\hline 37 & Trimeric_dutpase superfamily & $2.62 \mathrm{E}-23$ & 89.0534 & Cl00493 \\
\hline 45 & TS_Pyrimidine_hmase & $5.70 \mathrm{E}-91$ & 268.76 & Cd00351 \\
\hline 45 & TS_Pyrimidine_hmase superfamily & 5.17E-137 & 387.525 & Cl19097 \\
\hline 48 & NTP-ppase superfamily & 0.002418 & 35.1816 & Cl16941 \\
\hline 49 & ABC_atpase superfamily & $2.77 \mathrm{E}-17$ & 78.3824 & $\mathrm{Cl} 21455$ \\
\hline 49 & Uvrd_C_2 & $8.48 \mathrm{E}-08$ & 47.1547 & Pfam13538 \\
\hline 49 & Uvrd_C_2 superfamily & 8.48E-08 & 47.1547 & Cl22491 \\
\hline 49 & Aaa_30 & $2.77 \mathrm{E}-17$ & 78.3824 & Pfam13604 \\
\hline 49 & $\operatorname{Cog} 1112$ & 9.34E-05 & 43.4113 & $\operatorname{Cog} 1112$ \\
\hline 51 & DNA_pol_A superfamily & $1.80 \mathrm{E}-26$ & 110.198 & Cl02626 \\
\hline 51 & DNAq_like_exo superfamily & 0.0005505 & 40.4172 & $\mathrm{Cl} 10012$ \\
\hline 55 & Prict_1 & $1.28 \mathrm{E}-07$ & 47.6526 & Pfam08708 \\
\hline 55 & Prict_1 superfamily & $1.28 \mathrm{E}-07$ & 47.6526 & Cl07362 \\
\hline 56 & ABC_atpase superfamily & 0.0005674 & 38.4072 & $\mathrm{Cl} 21455$ \\
\hline 63 & Prk14085 & 0.0005556 & 34.1837 & Prk14085 \\
\hline 64 & DUF2829 & $1.18 \mathrm{E}-16$ & 66.5176 & Pfam11195 \\
\hline 64 & DUF2829 superfamily & $1.18 \mathrm{E}-16$ & 66.5176 & Cl12744 \\
\hline 65 & Parbc & 0.0004658 & 37.3039 & Pfam02195 \\
\hline 65 & Parbc superfamily & 0.0003729 & 37.2839 & $\mathrm{Cl} 02129$ \\
\hline 66 & DUF1178 & 0.0021343 & 34.0766 & Pfam06676 \\
\hline 67 & Extradiol_Dioxygenase_3B_like superfamily & 0.0057676 & 34.7714 & Cl00599 \\
\hline 69 & Lt_gewl & $1.36 \mathrm{E}-18$ & 80.5286 & Cd00254 \\
\hline 69 & Lysozyme_like superfamily & $1.36 \mathrm{E}-18$ & 80.5286 & Cl00222 \\
\hline 70 & Polyadenylate-binding_protein_3 & 0.0067594 & 34.0122 & Tigr01628 \\
\hline 72 & DUF3584 & 0.0060894 & 36.9891 & Pfam 12128 \\
\hline 74 & Hypothetical_protein & $5.26 \mathrm{E}-76$ & 237.638 & Tigr04387 \\
\hline 74 & P22_coatprotein superfamily & $5.26 \mathrm{E}-76$ & 237.638 & $\mathrm{Cl} 22542$ \\
\hline 78 & $\operatorname{Cog} 4913$ & 0.001198 & 41.1603 & $\operatorname{Cog} 4913$ \\
\hline 79 & Prk09039 & 0.000734 & 37.6381 & Prk09039 \\
\hline 80 & Glyco_hydro_108 superfamily & $9.31 \mathrm{E}-23$ & 86.0288 & Cl09583 \\
\hline 80 & PG_binding_3 superfamily & 0.0001066 & 38.2277 & Cl09627 \\
\hline
\end{tabular}


Table 6 Delftia phage RG 2014 annotation using conserved domain database* (Continued)

\begin{tabular}{lllll}
\hline Gene & Evidence & E value & Bit Score & Accession \\
\hline 86 & COG5362 superfamily & $3.02 \mathrm{E}-08$ & 51.3532 & Cl02216 \\
88 & Phage_gp49_66 & $2.28 \mathrm{E}-21$ & 85.3759 & Pfam13876 \\
88 & Phage_gp49_66 superfamily & $2.28 \mathrm{E}-21$ & 85.3759 & Cl10351 \\
\hline
\end{tabular}

*Evidence of gene functions provided by blast analysis using conserved domain database $\left(e\right.$-value $\left.\leq 10^{-5}\right)$

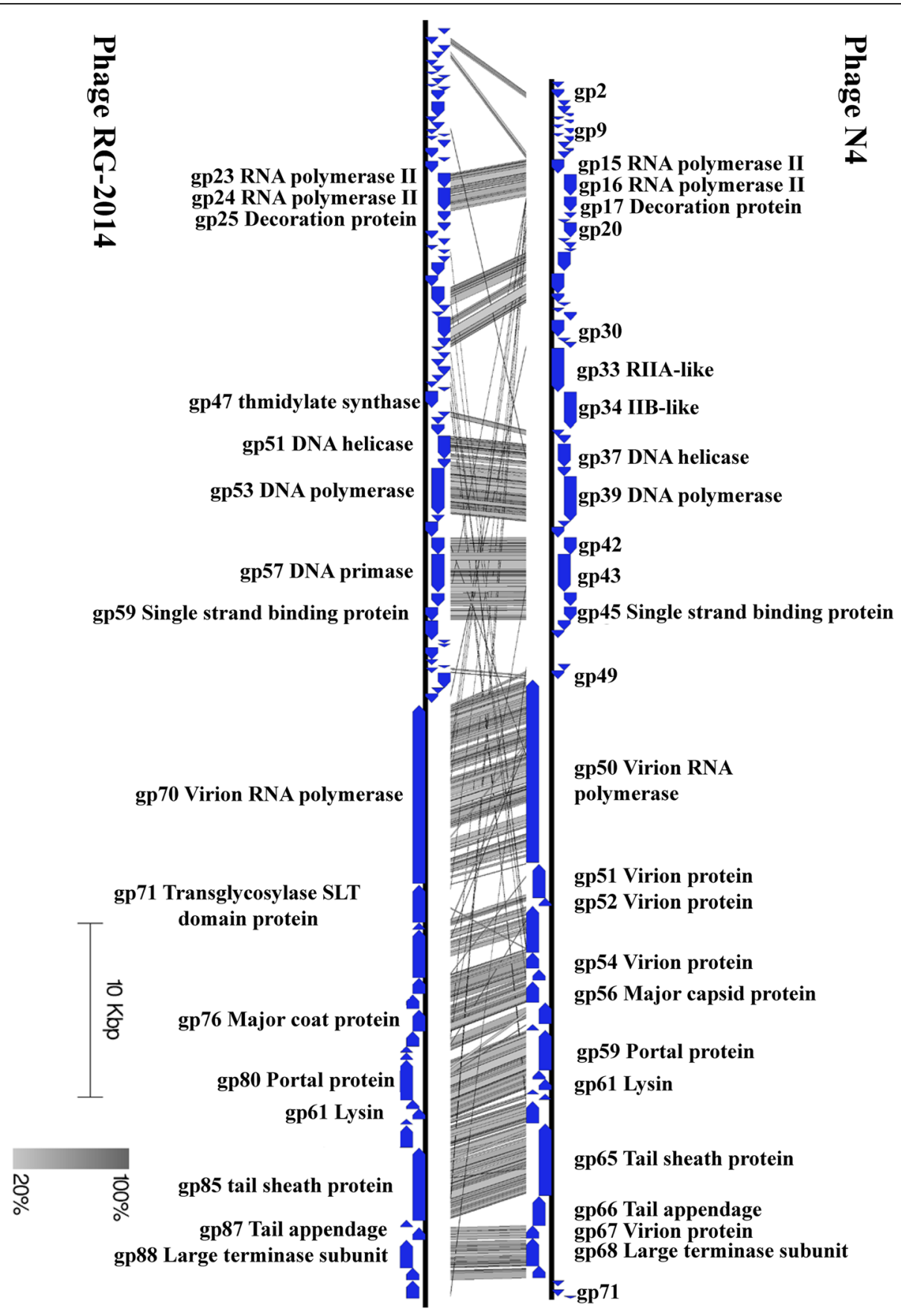

Fig. 3 Whole genome comparison of Delftia phage RG-2014 (KM872991.2) phage to E. coli phage N4 (NC_008720). The Figure was generated with Easyfig [38]. Genomes were aligned using Easyfig [38]. The functions of genes in phage N4 are shown above and predicted functions of RG-2014 genes are indicated below the maps 
sufficiently large for such a determination) to be present in rather distantly related prophages that have other similarities to the N4-like phages including a prophage encoded vRNAP, suggesting that there are currently undescribed temperate phages that are very distantly related to the N4-like phage group (our unpublished observation). Nonetheless, among the 143 currently available genomes from the Comamonadaceae bacterial family (including eight Delftia genomes) the best-encoded protein matches have only $22 \%$ identity to the phage RG-2014 MCP. We conclude that phage RG-2014 is virulent.

The N4-like phage group is clearly well separated from the other known tailed bacteriophages [11, 28], but the taxonomic status of different phages within the group remains less understood. Unlike some other tailed phage types, the N4-like phages include members that infect a wide range of bacterial hosts in the Alphaproteobacteria,
Betaproteobacteria and Gammaproteobacteria classes $[25,28]$. Fig. 4 shows a dotplot of a diverse sample of N4-like phage genomes that illuminates several aspects of the phages in this group (no diagonal lines are present when comparison is with other tailed phage types, data not shown). First, phage RG-2014 is not particularly closely related to any of the other currently known N4like phages; its closest, but nonetheless rather distant, relatives are Achromobacter phages JWDelta, JWAlpha and $ø$ Axp-1. We note that these four phages infect members of the Betaproteobacteria. A second conclusion that can be drawn from fig. 4 is that genome similarity within this group of phages generally parallels the relatedness of their hosts. The various subtypes of the N4-like phage group (separated by thick red lines in the figure) are usually restricted to single genus; the one current exception to this rule is the relatively close relationship between Vibrionaceae phage VPB47 and

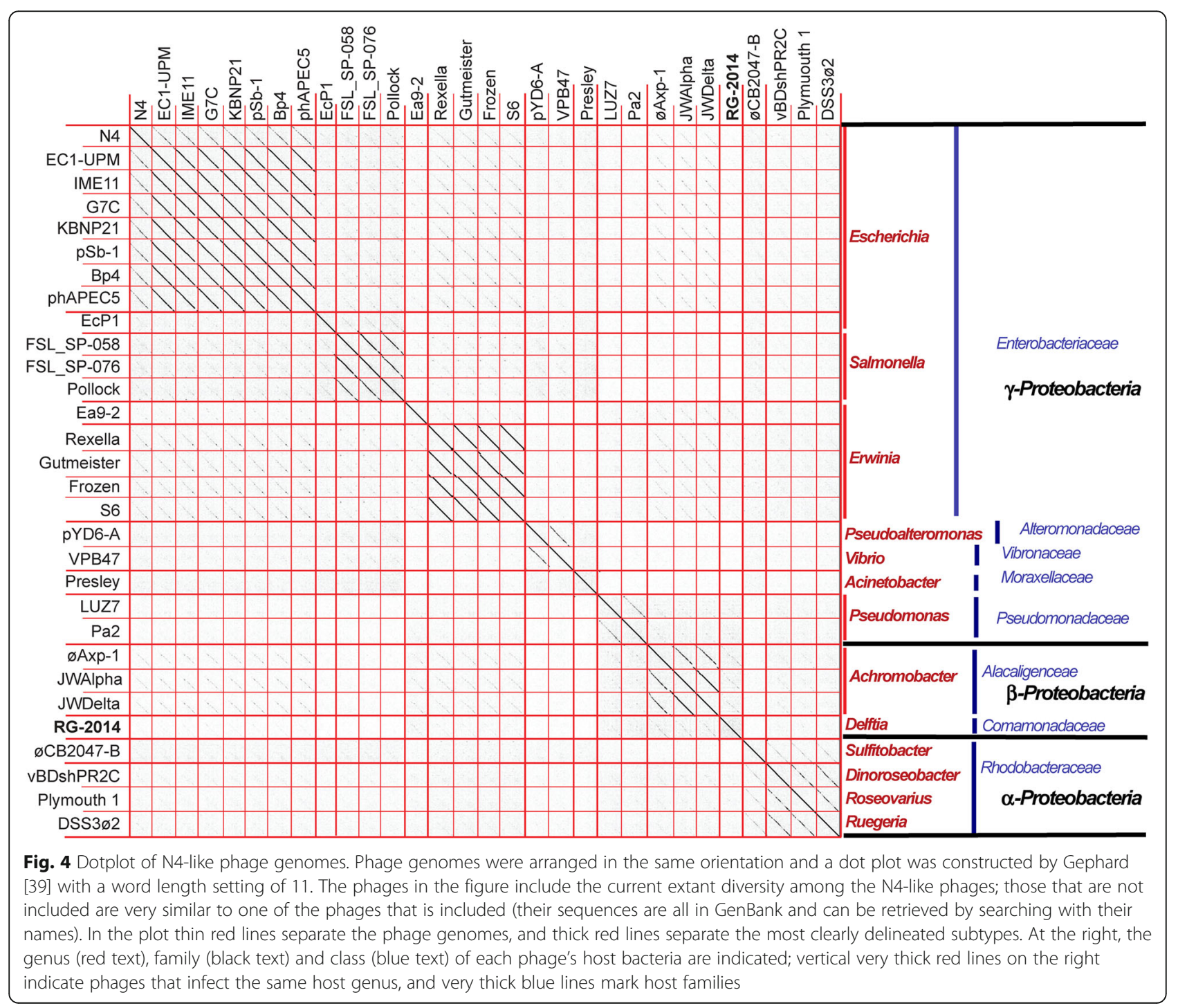


Pseudoalteromonadaceae phage pYD6-A. It thus appears that recent "jumping" of these phages between taxonomically distant hosts is not common. On the other hand, more than one N4-like phage subtype can infect a given host genus; for example, Escherichia and Erwinia N4-like phages are clearly present as two subtypes (e.g. the Escherichia N4/EcP1 and Erwinia Ea9-2/S6 pairs). More distant host relationships are complex. Very weak diagonal similarity lines are present when the Escherichia (phage N4 subtype), Erwinia and Achromobacter N4-like phages are compared. These could tentatively correspond to members of the proposed Enquatravirinae subfamily [28].

\section{Conclusions}

The D. tsuruhatensis infecting phage RG-2014 belongs to the Podoviridae viral family. The phage RG-2014 genome sequence shows significant synteny and sequence similarity to E. coli bacteriophage $\mathrm{N} 4$ and other members of the N4-like group of tailed phages; this clearly demonstrates phage RG-2014's membership in this group. Our analysis confirms that phages in the virulent N4-like group are widely present in the wild. The members of the N4-like group infect bacterial hosts in several classes within the Proteobacteria phylum. Their virulent nature, widespread distribution and efficient infection suggest that members of this group will be useful in many bacterial control situations.

\section{Abbreviations}

ARB: Antibiotic Resistant Bacteria; COG: Cluster of Orthologous Groups; ORF: Open reading frame; RNAP: RNA polymerase

\section{Acknowledgements \\ This research was conducted under the CAREER funding mechanism of NSF. This project was awarded to Dr. Ramesh Goel. Mr. Eddie B. Gilcrease was supported under a $\mathrm{NHH}$ funded project with Dr. Sherwood Casjens as the principal investigator. Any opinions expressed in this paper are those of the authors and do not necessarily reflect the views of the agency; therefore, no official endorsement should be inferred. Any mention of trade names or commercial products does not constitute endorsement or recommendation for use.}

\section{Funding}

This research was partially supported by National Science Foundation (NSF) Grant 1,055,786 and 58,501,574 to RG and NIH grant GM1 14817 to SRC. The views and opinions expressed in this manuscript are those of authors and do not necessarily relate to the funding agency.

\section{Authors' contributions \\ ASB design the study, performed the experiments, analyzed data, and wrote the manuscript. AMM helped with the experiments and writing of the manuscript. EBG helped with the PCR assays for finishing up the genome. SRC participated in the experiments, helped in analyzing the data, and writing the manuscript. MII reviewed the manuscripts and provided valuable comments. RG helped in designing the study, coordinated the project and assisted in drafting the manuscript. All authors have read and approved the final manuscript.}

\section{Competing interests}

The authors declare that they have no financial and non-financial competing interests.

\section{Publisher's Note}

Springer Nature remains neutral with regard to jurisdictional claims in published maps and institutional affiliations.

\section{Author details}

'Department of Civil and Environmental Engineering, University of Utah, Salt Lake City, UT, USA. ${ }^{2}$ Division of Microbiology and Immunology, Pathology Department, University of Utah School of Medicine, Salt Lake City, UT, USA. ${ }^{3}$ Department of Biology, University of Utah, Salt Lake City, UT, USA. ${ }^{4}$ Bigelow Laboratory for Ocean Science, 60 Bigelow Dr., East Boothbay, ME, USA.

${ }^{5}$ Department of Civil, Environmental, and Construction Engineering,

University of Central Florida, 12800 Pegasus Dr., Room 340, Orlando, FL, USA.

Received: 23 May 2017 Accepted: 24 November 2017

Published online: 18 December 2017

\section{References}

1. Centers for Disease Control and Prevention (CDC). Antibiotic resistance threats in the United States, 2013. Atlanta: CDC; 2015. p. 2013.

2. Motlagh AM, Bhattacharjee AS, Goel R. Biofilm control with natural and genetically-modified phages. World J Microb Biot. 2016;32:1-10. doi:10.1007/s11274-016-2009-4

3. Juárez-Jiménez B, Manzanera M, Rodelas B, Martínez-Toledo MV, GonzalezLópez J, Crognale S, Pesciaroli C, Fenice M. Metabolic characterization of a strain (BM90) of Delftia tsuruhatensis showing highly diversified capacity to degrade low molecular weight phenols. Biodegradation. 2010;1:475-89. doi:10.1007/s10532-009-9317-4

4. Morel MA, Ubalde MC, Braña V, Castro-Sowinski S. Delftia sp. JD2: a potential $\mathrm{Cr}(\mathrm{VI})$-reducing agent with plant growth-promoting activity. Arch Microbiol. 2011;1:63-8. doi:10.1007/s00203-010-0632-2.

5. Calderón K, Reboleiro-Rivas P, Rodríguez FA, Poyatos JM, González-López J, Rodelas B. Comparative analysis of the enzyme activities and the bacterial community structure based on the aeration source supplied to an MBR to treat urban wastewater. J Environ Manag. 2013;15:471-9. doi:10.1016/j. jenvman.2013.05.048.

6. Safarik J, Phipps DW. Microbial diversity in a three stage reverse osmosis system. In: Water Reuse \& Desalination Research Conference; 2013.

7. Kjeldsen KU, Kjellerup BV, Egli K, Frølund B, Nielsen PH, Ingvorsen K. Phylogenetic and functional diversity of bacteria in biofilms from metal surfaces of an alkaline district heating system. FEMS Microbiol Ecol. 2007;61: 384-97. doi:10.1111/j.1574-6941.2006.00255.x.

8. Preiswerk B, Ullrich S, Speich R, Bloemberg GV, Hombach M. Human infection with Delftia tsuruhatensis isolated from a central venous catheter. J Med Microbiol. 2011;60:246-8. https://doi.org/10.1099/jmm.0.021238-0.

9. Tabak O, Mete B, Aydin S, Mandel NM, Otlu B, Ozaras R, Tabak F. Portrelated Delftia tsuruhatensis bacteremia in a patient with breast cancer. New Microbiol. 2013;36:199-201.

10. Bhattacharjee AS, Choi J, Motlagh AM, Mukherij ST, Goel R. Bacteriophage therapy for membrane biofouling in membrane bioreactors and antibiotic-resistant bacterial biofilms. Biotechnol Bioeng. 2015:1:1644-54. doi:10.1002/bit.25574.

11. Grose JH, Casjens SR. Understanding the enormous diversity of bacteriophages: the tailed phages that infect the bacterial family Enterobacteriaceae. Virology. 2014;468:421-43.

12. Earnshaw W, Casjens S, Harrison SC. Assembly of the head of bacteriophage P22: $x$-ray diffraction from heads, proheads and related structures. J Mol Biol. 1976;104:387-410. doi:10.1016/0022-2836(76)90278-3.

13. Casjens SR, Gilcrease EB. Determining DNA packaging strategy by analysis of the termini of the chromosomes in tailed-bacteriophage virions. In bacteriophages 2009 (pp. 91-111). Humana Press.

14. Sanger F, Nicklen S, Coulson AR. DNA sequencing with chain-terminating inhibitors. Proc Natl Acad Sci U S A. 1977;74:5463-7.

15. Delcher AL, Bratke KA, Powers EC, Salzberg SL. Identifying bacterial genes and endosymbiont DNA with glimmer. Bioinformatics. 2007;23:673-9.

16. Besemer J, Lomsadze A, Borodovsky M. GeneMarkS: a self-training method for prediction of gene starts in microbial genomes. Implications for finding sequence motifs in regulatory regions. Nucleic Acids Res. 2001;29:2607-18. doi:10.1093/nar/29.12.2607

17. Conesa A, Götz S, García-Gómez JM, Terol J, Talón M, Robles M. Blast2GO: a universal tool for annotation, visualization and analysis in functional genomics research. Bioinformatics. 2005;21:3674-6. doi:10.1093/bioinformatics/bti610. 
18. Edgar RC. Search and clustering orders of magnitude faster than BLAST. Bioinformatics. 2010;26:2460-1. doi:10.1093/bioinformatics/btq461.

19. Laslett D. Canback: BARAGORN, a program to detect tRNA genes and tmRNA genes in nucleotide sequences. Nucleic Acids Res. 2004;32:11-6. doi:10.1093/nar/gkh152.

20. Schattner P, Brooks AN, Lowe TM. The tRNAscan-SE, snoscan and snoGPS web servers for the detection of tRNAs and snoRNAs. Nucleic Acids Res. 2005;33:686-9. doi:10.1093/nar/gki366.

21. Tatusov RL, Galperin MY, Natale DA, Koonin EV. The COG database: a tool for genome-scale analysis of protein functions and evolution. Nucleic Acids Res. 2000;1:33-6. doi:10.1093/nar/28.1.33

22. Galperin MY, Makarova KS, Wolf Yl, Koonin EV. Expanded microbial genome coverage and improved protein family annotation in the COG database. Nucleic Acids Res. 2014;43:261-9. doi:10.1093/nar/gku1223.

23. Wu S, Zhu Z, Fu L, Niu B, Li W. WebMGA: a Customizable Web Server for Fast Metagenomic Sequence Analysis. BMC Genomics. 2011;12:444. doi:10.1186/1471-2164-12-4.

24. Wittmann J, Dreiseikelmann B, Rohde M, Meier-Kolthoff JP, Bunk B, Rohde C First genome sequences of Achromobacter phages reveal new members of the N4 family. Virol J. 2014;11:422X-11. doi:10.1186/1743-422X-11-14.

25. Ceyssens PJ, Brabban A, Rogge L, Lewis MS, Pickard D, Goulding D, Dougan G, Noben JP, Kropinski A, Kutter E, Lavigne R. Molecular and physiological analysis of three Pseudomonas aeruginosa phages belonging to the "N4-like viruses". Virology. 2010;15:26-30. doi:10.1016/.jvirol.2010.06.011.

26. Zhao Y, Wang K, Jiao N, Chen F. Genome sequences of two novel phages infecting marine roseobacters. Environ Microbiol. 2009:11:2055-64. doi:10.1111/j.1462-2920.2009.01927.x.

27. Gan HM, Sieo CC, Tang SGH, Omar AR, Ho YW. The complete genome sequence of EC1-UPM, a novel N4-like bacteriophage that infects Escherichia coli O78: K80. Virol J. 2013;10:1. doi:10.1186/1743-422X-10-308.

28. Wittmann J, Klumpp J, Switt AlM, Yagubi A, Ackermann HW, Wiedmann M, Svircev A, Nash JH, Kropinski AM. Taxonomic reassessment of N4-like viruses using comparative genomics and proteomics suggests a new subfamily"Enquartavirinae". Arch Virol. 2015;160:3053-62. doi:10.1007/s00705-015-2609-6.

29. Hendrix RW, Smith MC, Burns RN, Ford ME, Hatfull GF. Evolutionary relationships among diverse bacteriophages and prophages: all the world's a phage. Proc Natl Acad Sci U S A. 1999:96:2192-7.

30. Casjens $\mathrm{S}$, Hatfull $\mathrm{G}$, Hendrix R. Evolution of dsDNA tailed-bacteriophage genomes. Semin Virol. 1992;3:383-97.

31. Casjens SR. Comparative genomics and evolution of the tailed-bacteriophages. Curr Opin Microbiol. 2005;8:451-8. doi:10.1016/j.mib.2005.06.014.

32. Kazmierczak KM, Rothman-Denes LB. Bacteriophage N4. The bacteriophages 2006 (pp. 302-314). Oxford University Press.

33. De-Paepe M, Taddei F. Viruses' life history: towards a mechanistic basis of a trade-off between survival and reproduction among phages. PLoS Biol. 2006:4:e193. doi:10.1371/journal.pbio.0040193.

34. Bailly-Bechet $M$, Vergassola M, Rocha E. Causes for the intriguing presence of tRNAs in phages. Genome Res. 2007:17:1486-95. doi:10.1101/gr.6649807.

35. Angellotti MC, Bhuiyan SB, Chen G, Wan XF. CodonO: codon usage bias analysis within and across genomes. Nucleic Acids Res. 2007:35:132-6. doi:10.1093/nar/gkm392.

36. Choi KH, McPartland J, Kaganman I, Bowman VD, Rothman-Denes LB, Rossmann MG. Insight into DNA and protein transport in double-stranded DNA viruses: the structure of bacteriophage N4. JMol Biol. 2008;378:726-36. doi:10.1016/j.jmb.2008.02.059.

37. Casjens SR, Grose JH. Contributions of P2-and P22-like prophages to understanding the enormous diversity and abundance of tailed bacteriophages. Virology. 2016;496:255-76.

38. Sullivan MJ, Petty NK, Beatson SA. Easyfig: a genome comparison visualizer. Bioinformatics. 2011;27:1009-10. doi:10.1093/bioinformatics/btr039.

39. Krumsiek J, Arnold R, Rattei T. Gepard: a rapid and sensitive tool for creating dotplots on genome scale. Bioinformatics. 2007;23:1026-8. doi:10.1093/ bioinformatics/btm039.

40. King AM, Lefkowitz E, Adams MJ, Carstens EB, editors. Virus taxonomy: ninth report of the international committee on taxonomy of viruses. San Diego: Elsevier; 2012.

\section{Submit your next manuscript to BioMed Central and we will help you at every step:}

- We accept pre-submission inquiries

- Our selector tool helps you to find the most relevant journal

- We provide round the clock customer support

- Convenient online submission

- Thorough peer review

- Inclusion in PubMed and all major indexing services

- Maximum visibility for your research

Submit your manuscript at www.biomedcentral.com/submit

) Biomed Central 